Sustainable Development and Planning X 599

\title{
THE ENVIRONMENTAL AND SOCIAL ROLE OF SEMI-OPEN SPACES IN VERNACULAR ARCHITECTURE OF THE EASTERN MEDITERRANEAN AREA: THE CASE OF CYPRUS
}

\author{
MARIA PHILOKYPROU \& AIMILIOS MICHAEL \\ Department of Architecture, University of Cyprus, Cyprus
}

\begin{abstract}
Semi-open spaces largely incorporated in vernacular dwellings formed important social and environmental architectural features throughout centuries. The warm climate of the Eastern Mediterranean area and the need for outdoor protected spaces led to a widespread use of semi-open spaces in the vernacular architecture of this region. Semi-open spaces can be found in a variety of typologies in terms of their geometry and layout, their relation to other closed and open spaces, as well as their function. These spaces constitute vital parts of the every-day life of the occupants, becoming essential activity and social-gathering areas. This paper focuses on the environmental and social role of semi-open spaces in the vernacular architecture of Cyprus, an island in the Eastern Mediterranean area. For the needs of this research, environmental monitoring equipment was installed in various closed and semi-open spaces. The study established the significant environmental role of semi-open spaces since these spaces serve as microclimatic regulators by mitigating high and low temperature. In order to preserve and enhance the environmental role of semi-open spaces, special design and construction measures need to be taken during the conservation process.
\end{abstract}

Keywords: semi-open spaces, environmental and social role, vernacular architecture, microclimatic.

\section{INTRODUCTION}

Semi-open spaces constitute important architectural and typological elements of the vernacular dwellings of Cyprus. These spaces diachronically appear in the Eastern Mediterranean area as they respond to the mild climatic conditions and to an introverted way of life. They were incorporated in domestic as well as public structures from the Prehistoric period onwards. In Classical Greek domestic structures semi-open spaces appear in the form of a colonnade called pastas, usually south-oriented, offering protection from the intense solar radiation [1]. In Hellenistic as well as in Roman domestic buildings, they take the form of a peristyle around the central courtyard [2].

In Cyprus, semi-open spaces appeared during the Prehistoric period, but they were widely used in the Roman domestic houses in the form of a peristyle. Later on, during Medieval times, they took the form of pass-through vaulted semi-open wide corridors which provided direct access from the street to the internal courtyard. At the same time semi-open spaces appeared in the form of pointed arcades, mainly on the elevations facing the dwelling's internal courtyard. More recently in the 19th and the beginning of the 20th centuries, these spaces have been incorporated into the Cypriot vernacular architecture.

Semi-open spaces constitute important environmental as well as functional elements in vernacular architecture. They serve as circulation spaces, as transitional areas between indoors and outdoors, they host household and agricultural activities and function as social gathering spaces. At the same time, they serve as microclimatic regulators, providing protection from the sun and rain thus mediating the outdoor environmental conditions. Despite their functional and environmental advantages, the incorporation of semi-open spaces in contemporary domestic architecture is very limited. There is also a need for a more 
in-depth study of all the different forms of semi-open spaces in terms of their environmental and social role in vernacular architecture of the Eastern Mediterranean area.

This study aims to investigate with a systematic and holistic approach, the different typologies of semi-open spaces identified in the vernacular architecture of Cyprus. The study presented herein investigates both rural and urban dwellings from different climatic and geomorphological areas of the island. It aims to connect the environmental assets of semiopen spaces to their typological characteristics as well as to their functional and social aspects. In order to achieve this, architectural characteristics and typological arrangements, i.e. geometry, size, orientation, materials and construction techniques were studied in parallel to the microclimatic conditions, i.e. natural ventilation and lighting, shading and insolation etc. Moreover, the study investigates the contemporary interventions to these spaces carried out by the users of the dwellings and suggests design guidelines towards a more environmentally friendly approach during conservation processes.

The current research constitutes the very first systematic and scientific analysis of semiopen spaces of vernacular rural and urban dwellings in Cyprus. The results derived from the current study can also be applied to other areas of the Eastern Mediterranean region, where similar typologies and climatic conditions can be found.

\section{BACKGROUND - LITERATURE REVIEW}

The environmental behavior of semi-open spaces has been presented in many studies dealing with the environmental design strategies applied in the vernacular architecture of the Mediterranean region [3], [4]. According to a large number of researchers, semi-open spaces are located mainly on the south side of buildings providing shading during the cooling period. At the same time, their appropriate width enables desirable direct solar gains during the heating period [5]. The correlation between typological characteristics of semi-open spaces, e.g. their architectural layout, level of exposed areas and degree of exposure, and their orientation, has been the subject of many studies investigating the thermal performance of these spaces [6]-[9].

Apart from orientation and architectural layout, materials also have a considerable impact on the environmental performance of semi-open spaces [10]. More specifically, the environmental role of these spaces is connected to the use of local materials of high thermal mass. The thermal inertia of the building materials constitutes a suitable passive strategy for both the cooling and heating period in the Mediterranean climate as it maintains constant values of indoor temperature [11], [12]. Balaras [13] related the effectiveness of the thermal mass to many factors, such as climate conditions, thermal properties of materials, heat gains, ventilation, thermal insulation and occupancy. Moreover, Kalogirou et al. [14] argued for the potential of cooling load reduction when thermal mass is applied, highlighting the fact that diurnal temperature variations indicated in Mediterranean climate are ideal for the implementation of such a strategy.

Natural ventilation also constitutes an important environmental cooling strategy closely related to semi-open spaces as well as to the internal courtyard. A series of relevant studies demonstrate the positive contribution of natural ventilation to the creation of a thermally comfortable environment, through the regulation of indoor thermal comfort parameters, i.e., air temperature, mean radiant temperature, relative humidity and air speed [15]-[17]. More specifically, night ventilation is of particular importance to the thermal performance of vernacular architecture, especially during the cooling period. In summer nights, when outdoor temperatures are lower than indoor temperatures, natural ventilation can contribute to passive cooling. Santamouris and Wouters [18] in their study verified the congruency between local daily functions and regional environmental characteristics. Moreover, an 
extensive qualitative analysis of the bioclimatic design strategies of vernacular architecture in distinct climatic regions was carried out by Bodach et al. [19] providing an overview of aspects affecting the thermal performance of the buildings under investigation which included cultural issues, geographical diversity, local materials and climate.

\section{RESEARCH METHODOLOGY}

The investigation of semi-open spaces in vernacular dwellings in Cyprus is part of a wider research performed on the vernacular architecture in different geomorphological areas and climatic zones in the island. Cyprus has typical Mediterranean climate, characterized as warm with hot summers, moderate and rather rainy winters with large diurnal fluctuations. Prevailing winds in the island blow predominantly southwest and east during the winter, west and north during the summer, and west and northeast during the spring and fall seasons.

In the framework of this research, the different types of semi-open spaces incorporated into the vernacular architecture of Cyprus were initially studied through a literature investigation. For the needs of the field study, characteristic rural and urban settlements located in the central lowlands (i.e. Chrysaliniotissa and Kaimakli area in the urban centre of Nicosia, as well as Pera Orinis and Kapedes rural settlements), in the southern coast region (i.e., Maroni, Kalavassos and Ayia Anna rural settlements) and the central highlands (i.e. Askas and Kakopetria rural settlements) were selected. The investigation of typical urban and rural settlements all over the island was followed by the selection of representative dwellings in each area under study. The incorporation of different typologies of semi-open spaces was taken into consideration during the selection of case study dwellings for an indepth investigation. Finally, data sheets including all the architectural and environmental features were prepared for each selected case study [20], [21].

In the second stage of the field study, a sample of dwellings that incorporate different typologies of semi-open spaces was selected from the different areas under investigation, for a monitoring of environmental parameters. Temperature and relative humidity USB data loggers (USB-2-LCD, USB-1-PRO) were placed in indoor and semi-open spaces, in order to record temperature and relative humidity. The data loggers were located $1.5 \mathrm{~m}$ above floor level and were protected from direct solar radiation. The semi-open spaces included in the environmental quantitative study were selected to vary in terms of architectural and environmental characteristics, thus allowing comparative analysis. At the same time, for comparison reasons, weather stations (Davis Vantage Pro2 Plus 6162 Wireless) were installed in the different areas under study for the acquisition of climatic data of the external environmental conditions, i.e., air temperature, relative humidity, global solar radiation, wind speed and direction, and rain. Environmental measurements were taken during an entire year covering the hot summer period, the cold winter period and the mid-seasons.

The research results were mainly based on remarks derived from comparative analysis between different case studies following specific criteria. More specifically, comparative analysis of data recorded in vernacular dwellings incorporating semi-open spaces of the same typology but of different orientations, as well as, semi-open spaces of the same orientation but of different typology. In addition, semi-open spaces that have undergone contemporary interventions, i.e., conversion of semi-open spaces into closed areas with the use of glazed surfaces, were investigated and compared with other semi-open spaces that retained their original character. The comparative analysis enabled the identification of parameters that affect the thermal performance of semi-open spaces, as well as the quantification of their positive or negative contribution. In addition, the effect of the environmental climatic conditions to the thermal performance of the semi-open spaces in different seasons was also examined. More specifically, the study was focused on the verification of the correlation 
between the daily maximum temperatures of semi-open spaces with the daily maximum temperatures and the daily mean solar radiation recorded in the external environment.

\section{RESULTS OF RESEARCH}

\subsection{Architectural characteristics - typological arrangements - function}

The overall investigation of the island's vernacular architecture conducted in the framework of this research has shown that semi-open transitional spaces appear in all rural and urban traditional settlements, but in a different frequency [22]. Semi-open spaces, located on different geomorphological areas and climatic zones all over the island, share some common characteristics while at the same time, demonstrate a variety in terms of typological and morphological characteristics as well as in terms of materials and construction techniques (Figs 1 and 2).

Semi-open spaces can be found more frequently in the context of rural and urban settlements of the lowland regions. The most distinctive semi-open typology in this climatic region is a longitudinal rectangular space shallow in plan with a wide frontage called iliakos, usually extended along the main living area of the dwelling (Figs 1(a) and 2(a)). The iliakos has at least one open side and it appears exclusively in the internal elevations of dwellings facing the courtyard and very frequently in front of main spaces (dichoro- double space room). This space was essential for everyday activities of the occupants e.g., agricultural, domestic (cooking, looming, weaving and washing), social (gathering area for both residents and visitors) as it offers an open-air, sun-protected space with sufficient daylighting levels [23]. Sometimes the iliakos incorporates a series of functional elements valuable for the everyday life of the inhabitants, such as traditional ovens, usually projected outside the useful area of the semi-open space. In the case of two-storey urban dwellings, staircases are to be found in the iliakos area for an external but still protected access to the second floor of the building.

On the other hand, in the coastal regions as well as in urban areas the most distinctive semi-open spatial configuration is a rectangular pass-through transitional space. This space is essentially a portico, which acts as a wide corridor connecting the street to the internal courtyard (Figs 1(b) and 2(b)). The portico incorporates a double timber door towards the street, which is permanently open on the side towards the courtyard. The portico was more widely incorporated in the urban dwellings at the end of the 19th and the beginning of the 20th century, when direct contact of the building volume with the street-front and access from it became an important element of the urban vernacular architecture, mainly for social reasons. Thus, the main building volume as well as the entrance to the house was located in the front part of the plot, in contact with the street, while the courtyard was located at the back of the plot. The entrance was achieved through the portico that divided the dwelling in the middle. This configuration created functional closed spaces on the two sides of the portico and thus the dwelling acquired a tripartite arrangement. There are also cases where functional closed spaces are found only on the one side of the portico and thus the dwelling has a dipartite arrangement [24]. In the case of two storey dwellings, the staircase was also located in the portico indicating that the space functioned as a circulation area rather than a gathering space.

Finally, there are some cases where the two above mentioned typologies of semi-open spaces, i.e. iliakos and portico, are combined into one semi-open space, leading to a more complex arrangement. These complex arrangements can be found more frequently in vernacular dwellings located in urban rather than rural settlements (Figs 1(c) and 2(c)). 


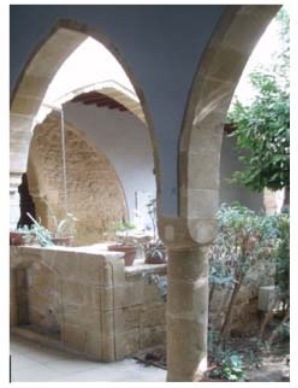

(a)

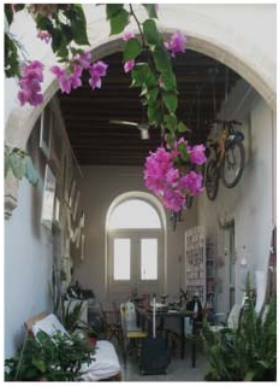

(b)

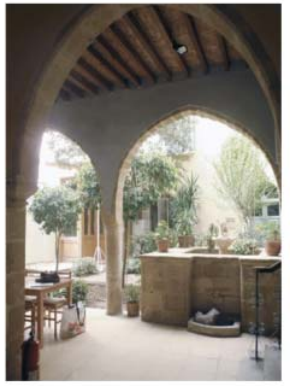

(c)

Figure 1: Semi-open spaces with different typological arrangements. (a) Iliakos; (b) Portico; and (c) Combination of iliakos and portico.

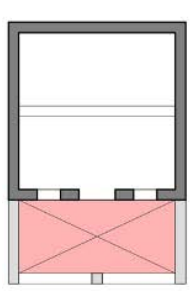

(a)

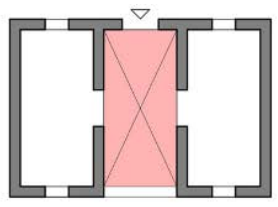

(b)

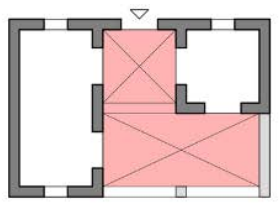

(c)

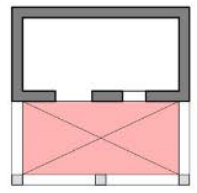

(d)

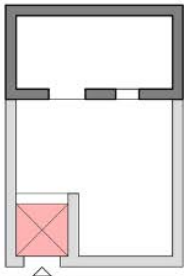

(e)

Figure 2: Plans of different typologies of semi-open spaces. (a) Iliakos; (b) Portico; (c) Combination of iliakos and portico; (d) Sahnisi (upper floor); and (e) Stegadi.

Semi-open spaces do not extensively appear in the vernacular dwellings of the mountainous areas due to the limited availability of land. Only a limited number of semiopen spaces can be found in the ground floor of mountainous vernacular dwellings. A covered space attached to the main entrance space of the courtyard towards the street, called stegadi, forms a distinctive semi-open feature of this region offering a protected entrance area (Fig. 2(e)). Such spaces can also be found more rarely in other areas. More often semi-open spaces can be found on the upper floor levels of dwellings (sometimes in the form of sahnisi) (Fig. 2(d)), where the basic functions of the dwelling took place, leaving the ground floor rooms for auxiliary uses. The access to the upper level was often achieved through open-air staircases leading to the above mentioned semi-open spaces.

Finally, there is another type of semi-open space, which is plant-covered, i.e., pergola with deciduous vine plants that is quite common in all Mediterranean climatic regions and is usually located either in the central courtyard or on top of flat roofs. According to relevant references [22], [27] and archival photographs, vine pergolas were a common element of the vernacular architecture during past decades, integrated in dwellings all over the island. Presently most of these components can be found primarily in the mountainous regions, while in other regions their presence is rather limited. 


\subsection{Building techniques and morphology of semi-open spaces}

The building techniques and materials used in the construction of semi-open spaces and consequently their morphology, vary across the different areas of the island. More specifically, the morphology of semi-open spaces depends on the geomorphology of each area and follows the available materials and construction techniques used in the vernacular dwellings of the specific region. For example, the semi-open spaces in mountainous areas are constructed with a timber post and beam structure (Fig. 3(a)). The roof is therefore supported by vertical and horizontal supporting elements, forming a timber colonnade. Timber structures can also be found in some cases in the lowland rural dwellings, usually in vernacular dwellings of the 19th century.

In the coastal areas however, as well as in the lowland rural and urban areas, the semiopen spaces (iliakoi), are usually configured by a series of stone-built arches, forming an arcade (Fig. 3(b)). These arcades are usually made of calcareous sandstone and rarely of bricks. In urban areas there are also some rare examples of composite structures where the roof of the semi-open spaces is supported by stone columns and horizontal timber beams.

The arcade of the iliakos demonstrates some interesting morphological characteristics. More frequently the arcade incorporates two stone semi-circular or pointed arches (Fig. 3(b)), but there are cases of one arch or a series of three or more arches like the examples found in the Ammochostos district (Fig. 3(c)). Special care was given to the morphology of the columns supporting the arches, especially for the decoration of a type of a simple capital formed at the point of the column where the arch began. Another interesting morphological feature is the appearance of a small round opening in the masonry between the two arches.

In some cases, semi-open spaces in the form of iliakos are found on two levels, i.e., ground and first floor giving the house an elaborate appearance. In these cases, the two iliakoi are either formed by timber members (mountainous areas) (Fig. 4(a)) or stone arches (lowland and coastal areas) (Fig. 4(b)). There are also some rare cases where the iliakos of the ground level is formed by an arcade or stone colonnade and the iliakos of the second floor is formed by timber elements thus reducing the loads of the structure (Fig. 4(c)).

The roofs of the semi-open spaces are either inclined or flat, depending on the prevailing construction technique of the area (Fig. 5). For the construction of the roofs of the semi-open spaces the same material and constructions techniques are used as in the rest roofs of the dwellings. A series of timber beams rest on the arcade or on the main timber beam placed at the open end of the semi-open space and on the building's masonry wall. Above these beams, multiple layers made of smaller timber members, brushes, reed battens, matting or timber planks rest, followed by layers of earth and ceramic tiles in the case of inclined roofs. The ends of the roof of semi-open spaces are also formed in a similar way as the ends of the other roofs of the dwellings.

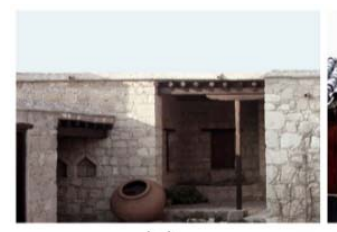

(a)

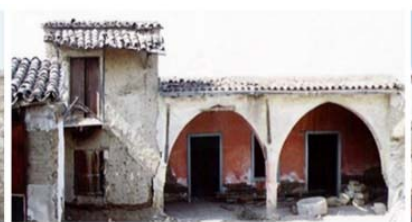

(b)

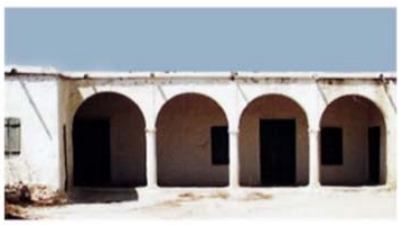

(c)

Figure 3: Different building techniques and materials used in the construction of semiopen spaces. (a) Timber post and beam structure; (b) Two stone pointed arches; and (c) A series of stone-built semi-circular arches. 


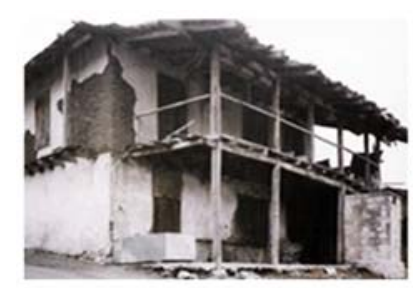

(a)

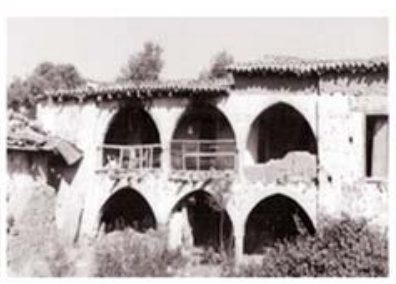

(b)

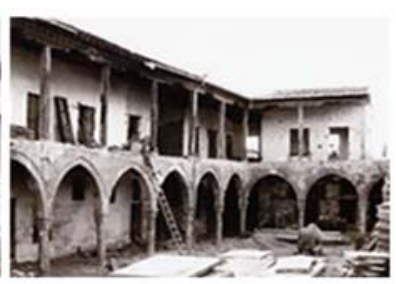

(c)

Figure 4: Archival photos of semi-open spaces found on two levels. (a) With timber elements; (b) With stone-built arches; and (c) Combination of arches and timber elements.
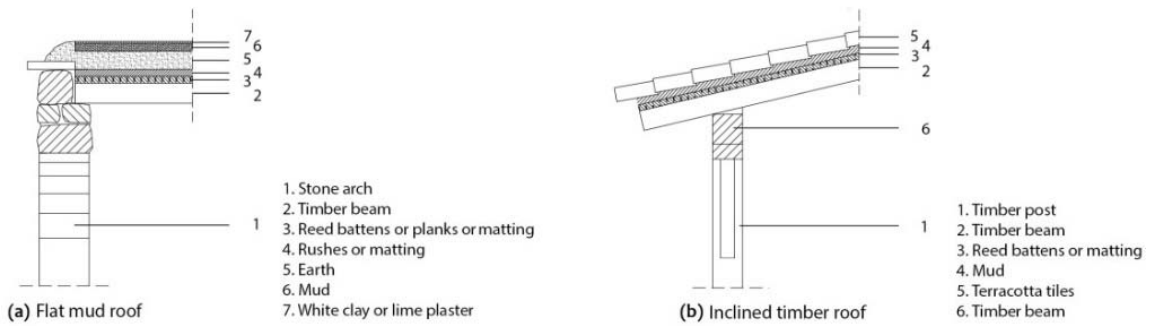

Figure 5: Structural details of the roofs of the semi-open spaces. (a) Flat mud roof; (b) Inclined timber roof.

\subsection{Environmental behaviour of the semi-open spaces (iliakos and portico)}

\subsubsection{Qualitative results}

The typology of the iliakos in vernacular residential architecture in all climatic zones of the island but especially in the lowland areas, is linked to climatic parameters [22]. The climate of lowland regions which is characterized by mild winters, hot and dry summers, intense solar radiation and extended periods of sunshine, led to a wide use of shaded and naturally ventilated semi-open spaces. The research results of the current study have shown that the majority of the semi-open spaces in the form of iliakos in rural settlements are oriented towards south. A large number of these semi-open spaces can also be found in east and southeast orientations. On the other hand, in the urban areas under investigation, the orientation of the iliakos seems to depend more on the urban fabric and not on climatic parameters, hence semi-open spaces with all orientations can be found.

The portico has also a distinctive environmental role, since its elongated configuration and the double-side openings at the two ends of the space allow for shading and enhanced natural ventilation. More specifically, the geometry of the portico, i.e. height to depth ratio, does not allow the penetration of sunrays in the interior of the space regardless of the orientation, and thus the orientation of the semi-open space in the form of a portico was not considered as an important parameter in both rural and urban settlements. As previously mentioned, especially in the urban areas, the urban fabric and the position of the dwelling in contact with the street plays a more important role in the orientation of the space than the climatic parameters. 
Deciduous vine pergolas mainly found in the central courtyards in the rural areas, offer all-year environmental performance by providing adequate shading and cooling via evapotranspiration of leafage during the hot, summer period while allowing solar penetration during the cold, winter period. In addition, the placement of such structures on top of flat roofs reduces the heat absorbed by the roofs' materials.

\subsubsection{Quantitative results}

During the monitoring process in a large number of selected rural and urban vernacular dwellings, emphasis was given to the examination of specific parameters that affect the thermal performance of semi-open spaces. Such parameters, with an important role in thermal performance are the orientation and the degree of enclosure of the semi-open spaces. The investigation also includes correlation studies analyses, aiming to define the effect of outdoor climatic parameters to the microclimatic conditions of the semi-open spaces, over different periods of the year. Finally, the impact of contemporary interventions on the thermal performance of semi-open spaces was examined through comparative analyses of recorded environmental data. The monitoring of the temperatures of indoor and semi-open spaces as well as of the external environment has shown that the diurnal temperature fluctuation in the semi-open spaces is smaller compared to that of the external environment, and slightly larger compared to that of the indoor spaces (Fig. 6). These results are attributed to the protective character of semi-open spaces and to the considerable thermal mass of the structure. Moreover, the semi-open spaces that were converted into closed areas with the use of glazed surfaces demonstrated an even smaller diurnal temperature fluctuation compared to the spaces that remain in their original semi-open state (Fig. 6).

\section{A. Orientation}

The results indicate that the south-oriented semi-open spaces exhibit generally higher temperatures and diurnal temperature fluctuations compared to the north-oriented spaces. This variation in temperatures of semi-open spaces with different orientation can be attributed to the impact of direct solar radiation. The research showed that semi-open spaces with southern orientation provide better thermal comfort during the heating period while spaces with a northern aspect offer greater thermal stability and a cooler space during the cooling period.

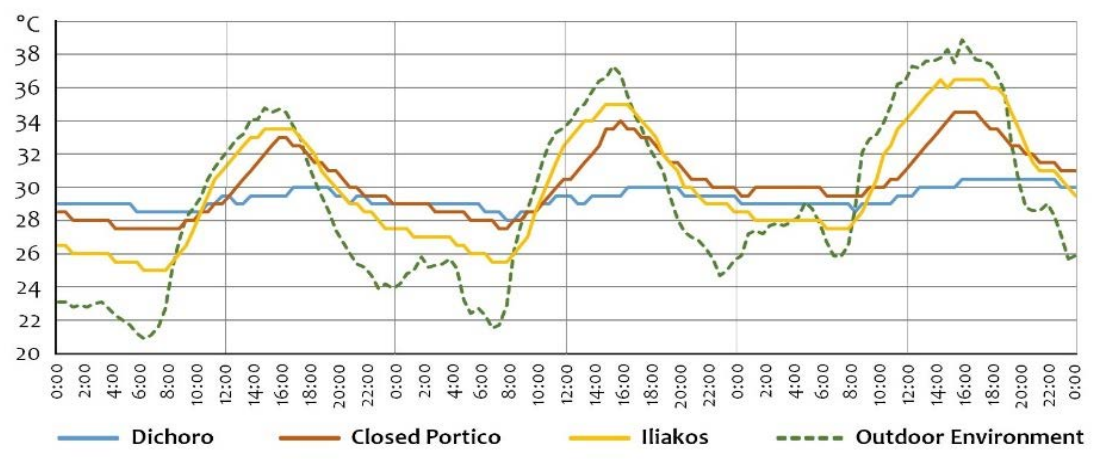

Figure 6: Diagram showing temperature fluctuation in semi-open spaces compared to closed areas and the outdoor environment. 


\section{B. Degree of enclosure}

In order to examine the influence of the architectural layout on microclimatic conditions, the two main typologies of semi-open spaces i.e., iliakos and portico, were monitored. Two cases of semi-open spaces facing internal courtyards with the same orientation and construction materials but with a different degree of enclosure (DoE), i.e., the ratio of the total surface areas over the exposed surface areas (openings including glazed surfaces) were investigated. Results showed a smaller fluctuation in the portico with a DoE equal to 8.0, compared to the iliakos with a DoE equal to 4.0. This is due to the greater depth and more protective character of the portico compared to the iliakos [25]. More specifically, the results indicate that the more enclosed the semi-open space is, the less exposed it becomes to outdoor climatic conditions exhibiting therefore, a thermal performance more similar to an indoor space. Due to the fact that the iliakos is less enclosed, more radiation is allowed to enter during the day as well as to escape during the night time, which results in a greater diurnal temperature fluctuation [26].

\section{Conversion of semi-open spaces into indoor spaces}

A comparative analysis was performed between the temperatures recorded in semi-open spaces, converted into indoor spaces by the addition of glazed surfaces (Fig.7) and the temperatures recorded in semi-open spaces, which are preserved in their original semi-open state [25], [26]. During the heating period (winter) the semi-open spaces converted into indoor spaces demonstrate better thermal performance during the day and night time compared to the spaces that remain in their original semi-open state. The results reveal that the large amount of solar heat gains absorbed by the glazed surfaces raises temperatures high above the temperatures of high-mass indoor spaces and semi-open spaces. Thus, during the heating period (winter) spaces with large glazed surfaces facing south could provide comfortable living conditions during daytime. In addition, during night time the mean minimum temperatures of the iliakos with glazed surfaces remain higher than the temperature of the iliakos that remain in their original state due to the protection offered by the glazing.

Large glazed surfaces facing south or southeast may cause an adverse thermal effect during the cooling period (summer) if precautions are not taken regarding shading and natural ventilation (Fig. 7(b) and 7(c)). The semi-open spaces converted into indoor spaces, show higher minimum temperature during the cooling period compared to the semi-open spaces that retain their original character, mainly due to the lack of night ventilation. The iliakos that retains its original semi-open character allows night ventilation, which contributes to the

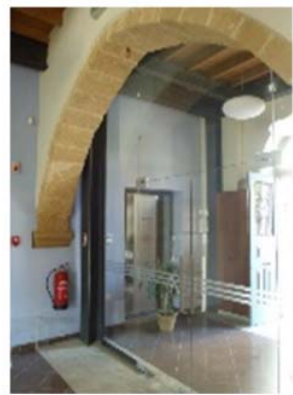

(a)

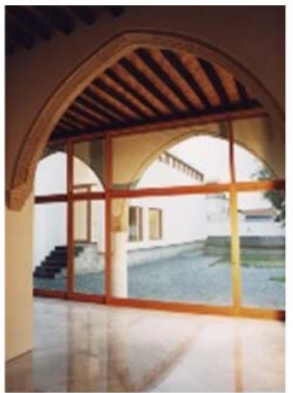

(b)

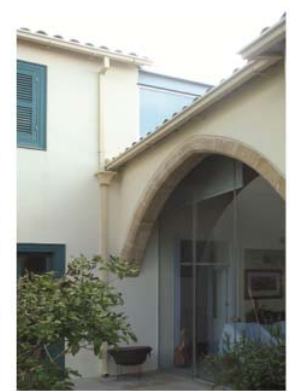

(c)

Figure 7: Views of semi-open spaces that were later closed by glazed surfaces. (a) Portico; (b) Iliakos; and (c) View of portico from the courtyard. 
reduction of the space's air temperature resulting from the significantly lower external environment temperatures during night time.

In order to compare the environmental impact of the different orientation of semi-open spaces converted into closed spaces with the addition of glazed surfaces, the thermal performances of two semi-open spaces in the form of porticos with similar architectural (DoE) and construction (thermal inertia of materials) characteristics but with different orientations, i.e., south and north orientation respectively, have been recorded. The southoriented closed portico exhibits a positive thermal performance during the heating period (winter). The existence of large south-facing glazed surfaces ensures significant potential for direct solar gains. In the cooling period (summer), this space maximizes the collection and storage process of direct solar gains and, combined with the lack of shading and natural ventilation, results in space overheating. On the other hand, the north-facing portico exhibits lower levels of thermal comfort during the heating period, compared to the south-facing portico. This is due to the lack of direct solar gains and of significant heat losses from the extensive south-facing glazed surfaces. In contrast, during the cooling period (summer), the north-facing portico recorded lower mean and minimum temperatures compared to the portico facing south, thus providing better living conditions.

\section{Outdoor climatic parameters and seasonal period changes}

The research has shown that maximum air temperatures of the semi-open spaces are directly related to the outdoor climatic parameters, while seasonal changes have a significant effect. A very strong linear correlation between maximum daily temperature of the case study spaces and maximum outdoor temperature is found for August (cooling period), October (midseason) and January (heating period) [26]. According to the findings of the research, the orientation and seasonal period are both strongly related to the impact of solar radiation on maximum temperatures of semi-open spaces. It is verified that maximum air temperatures of semi-open spaces with southern orientation are better correlated to mean global solar radiation due to their exposure to direct solar radiation. The gradual decrease of the variation between maximum air temperature of semi-open spaces and mean global solar radiation from the heating period to mid-season and to the cooling period can be attributed to two main factors: the solar altitude angle and the thermal inertia of materials.

During the heating period, deep penetration of direct solar radiation is allowed in the semiopen spaces due to the low solar altitude, increasing its effect on the maximum temperatures of semi-open spaces. However, during the cooling period semi-open spaces are protected due to the high solar altitude from direct solar radiation, which reduces its effect on maximum temperatures. Moreover, the high-mass walls enclosing the semi-open spaces absorb solar heat, thus minimizing the effect of mean global solar radiation especially during the cooling period.

\section{DISCUSSION AND CONCLUSIONS}

The research carried out revealed the various typologies of semi-open spaces incorporated in rural and urban dwellings located all over the island and underlined their social as well as their environmental role and contribution to the everyday life of the occupants. The use of these spaces in the domestic architecture of Cyprus since the antiquity and the frequency of their appearance in the vernacular dwellings during the last centuries shows the persistence of the inhabitants of the island in the old living habits as well as their ability to adapt to local environmental conditions. The research underlined the social advantages of these areas with their contribution to the agricultural and domestic activities and their positive contribution to the circulation in the dwellings. Moreover, the significant role of semi-open spaces as places 
of interaction as well as transitional spaces between the indoor and outdoor environment, offering a connection with the surrounding environment, was verified.

The function of the different semi-open spaces according to their architectural layout and their position in the dwelling was investigated and connected to the geomorphological and climatic conditions of each area under study. At the same time, the main parameters that affect the environmental role of these spaces - orientation, degree of enclosure, properties of materials used, and possible contemporary interventions, were investigated in detail. The significance of these spaces for extended periods of time within the Mediterranean climate, was also demonstrated.

The prevalence of the south as well as east and southeast orientations of the iliakos for better solar exploitation is in line with other previous research studies [25], [27]. The research has indicated that the mean temperature in semi-open spaces remained higher throughout the year, compared to the external environment hence these spaces offer better thermal conditions for the occupants during the heating period (winter). A better thermal comfort is provided by semi-open spaces with southern orientation during the heating period. Moreover, lower mean temperatures and greater thermal stability are offered by northern-oriented semiopen spaces during the cooling period. These research results are in line with other studies that link orientation with the thermal performance of semi-open spaces [10], [25]. At the same time, semi-open spaces of all orientations have shown a smaller diurnal temperature fluctuation compared to the external environment as they offer a more protected area compared to the environmental conditions. In the framework of this study, the positive contribution of night ventilation in the thermal performance of semi-open spaces during the cooling period has been revealed. The positive contribution of night ventilation is also underlined by other researchers dealing with vernacular architecture in the Eastern Mediterranean region or in other areas with similar typological and climatic characteristics [28]. The study has also shown the different environmental contribution of the portico compared to the iliakos due to the different layout and degree of enclosure that make the portico more favourable especially in coastal and urban areas. The correlation of the thermal performance of semi-open spaces with the degree of enclosure is also in line with other studies [7], [8] indicating that semi-open spaces with high DoE achieve greater moderation of the external thermal inflows with a given orientation. Correlation studies indicate that air temperature is the only outdoor climatic variable that has an all-year effect in maximum temperatures of semi-open spaces [26]-[28]. The strong linear correlation between maximum daily temperature of semi-open spaces and maximum outdoor temperature confirms the findings of other studies [27], [28] relating outdoor temperatures to the temperatures of semiopen spaces. The impact of contemporary interventions, i.e. the conversion of semi-open spaces into closed areas, on the thermal performance of vernacular dwellings was also investigated in detail. The positive contribution of glazed surfaces in south-oriented spaces during the heating period as well as the negative contribution of such interventions during the cooling period, was pointed out.

This study has shown that semi-open spaces are some of the most vital spaces of vernacular dwellings, playing an important role in everyday activities. Thus, special care should be given during the conservation process to the maintenance of semi-open spaces, avoiding any intervention that will alter the social as well as the environmental benefits provided to the occupants. At the same time, the detailed investigation on the environmental and social assets of these spaces will enhance the ongoing discussion for the incorporation of environmental and social aspects in the design process of contemporary buildings in order to achieve more environmentally responsive living environments. 


\section{ACKNOWLEDGEMENTS}

The research is based on the findings of two research programmes with the acronyms BioCultural and BioVernacular funded by the University of Cyprus, 2013-15 and by the Republic of Cyprus and the European Regional Development Fund, 2012-14, respectively.

\section{REFERENCES}

[1] Nevett, L., House and Society in the Ancient Greek World, Cambridge University Press, 2001.

[2] Watkin, D., A History of Western Architecture, Laurence King Publishing, 2005.

[3] Cañas, I. \& Martín, S., Recovery of Spanish vernacular construction as a model of bioclimatic architecture. Building and Environment, 39(12), pp. 1477-1495, 2004.

[4] Kolokotroni, M. \& Young, A.N., Guidelines for bioclimatic housing design in Greece. Building and Environment, 25(4), pp. 297-307, 1990. DOI: 10.1016/03601323(90)90003-a.

[5] Philokyprou, M., Michael, A., Savvides, A. \& Malaktou, E., Evaluation of bioclimatic design features of vernacular architecture in Cyprus. Case studies from rural settlements in different climatic regions. Proceedings of the 2nd International Conference on Preservation, Maintenance and Rehabilitation of Historic Buildings and Structures, pp. 999-1008, 2015.

[6] Chun, C., Kwok, A. \& Tamura, A., Thermal comfort in transitional spaces-basic concepts: Literature review and trial measurements. Building and Environment, 39(10), pp. 1187-1192, 2004. DOI: 10.1016/j.buildenv.2004.02.003.

[7] Sinou, M., Design and Thermal Diversity of Semi-Enclosed Spaces, Melrose Books: Cambridgeshire, 2007.

[8] Steemers, K. \& Steane, M. (eds), Environmental Diversity in Architecture, Spon Press: London, pp. 85-100, 2004.

[9] Savvides, A., Michael, A., Malaktou, E. \& Philokyprou, M., Examination and assessment of insolation conditions of streetscapes of traditional settlements in the Eastern Mediterranean area. Habitat International, 53, pp. 442-452, 2016. DOI: 10.1016/j.habitatint.2015.12.002.

[10] Potvin, A., The arcade environment. arq: Architectural Research Quarterly, 2(4), pp. 64-79, 1997. DOI: 10.1017/s1359135500001603.

[11] Cardinale, N., Rospi, G. \& Stefanizzi, P., Energy and microclimatic performance of Mediterranean vernacular buildings. The Sassi district of Matera and the Trulli district of Alberobello. Building and Environment, 59, pp. 590-598, 2013. DOI: 10.1016/j.buildenv.2012.10.006.

[12] Martín, S., Mazarrón, F.R. \& Cañas I., Study of thermal environment inside rural houses of Navapalos (Spain): The advantages of reuse buildings of high thermal inertia. Construction and Building Materials, 24(5), pp. 666-676, 2010. DOI: 10.1016/j.conbuildmat.2009.11.002.

[13] Balaras, C.A., The role of thermal mass on the cooling load of buildings. An overview of computational methods. Energy and Buildings, 24(1), pp. 1-10, 1996. DOI: 10.1016/0378-7788(95)00956-6.

[14] Kalogirou, S.A., Florides, G. \& Tassou, S., Energy analysis of buildings employing thermal mass in Cyprus. Renewable Energy, 27(3), pp. 353-368, 2002. DOI: 10.1016/s0960-1481(02)00007-1.

[15] Fabi, V., Andersen, R.V., Corgnati, S. \& Olesen, B.W., Occupants' window opening behaviour: A literature review of factors influencing occupant behaviour and models. Building and Environment, 58, pp. 188-198, 2012. 
DOI: 10.1016/j.buildenv.2012.07.009.

[16] Van Den Wymelenberg, K., Patterns of occupant interaction with window blinds: A literature review. Energy and Buildings, 51, pp. 165-176, 2012.

DOI: 10.1016/j.enbuild.2012.05.008.

[17] Michael, A., Demosthenous, D. \& Philokyprou, M., Natural ventilation for cooling in mediterranean climate: A case study in vernacular architecture of Cyprus. Energy and Buildings, 144, pp. 333-345, 2017. DOI: 10.1016/j.enbuild.2017.03.040.

[18] Santamouris, M. \& Wouters, P. (eds), Building Ventilation. The State of the Art, Earth Scan: UK, 2006.

[19] Bodach, S., Lang, W. \& Hamhaber, J., Climate responsive building design strategies of vernacular architecture in Nepal. Energy and Buildings, 81, pp. 227-242, 2014. DOI: 10.1016/j.enbuild.2014.06.022.

[20] Philokyprou, M., Savvides, A., Michael, A. \& Malaktou, E., Examination and assessment of the environmental characteristics of vernacular rural settlements: Three case studies in Cyprus. Vernacular Architecture: Towards a Sustainable Future, pp. 613-618, 2014. DOI: 10.1201/b17393-107.

[21] Philokyprou, M., Michael, A. \& Thravalou, S., Assessment of the bioclimatic elements of vernacular architecture. The historic centre of Nicosia, Cyprus. Proceedings of the International Conference on Conservation Regeneration Innovation, pp. 666-675, 2013.

[22] Philokyprou, M., Michael, A., Malaktou, E. \& Savvides, A., Environmentally responsive design in Eastern Mediterranean. The case of vernacular architecture in the coastal, lowland and mountainous regions of Cyprus. Building and Environment, 111, pp. 91-109, 2017. DOI: 10.1016/j.buildenv.2016.10.010.

[23] Michael, A., Heracleous, C., Thravalou, S. \& Philokyprou, M., Lighting performance of urban vernacular architecture in the East-Mediterranean area: Field study and simulation analysis. Indoor and Built Environment, 26(4), pp. 471-487, 2017. DOI: $10.1177 / 1420326 \times 15621613$.

[24] Demi, D. (ed.), The Walled City of Nicosia, A Typology Study. UNDP: Nicosia, 1997.

[25] Philokyprou, M., Michael, A., Thravalou, S. \& Ioannou, I., Thermal performance assessment of vernacular residential semi-open spaces in Mediterranean climate. Indoor and Built Environment, 27(8), pp. 1050-1068, 2017.

DOI: $10.1177 / 1420326 \times 17699037$.

[26] Malaktou, E., Philokyprou, M., Michael, A. \& Savvides, A., Environmental behaviour of semi-open spaces in Mediterranean vernacular architecture. The case of rural traditional dwellings of Cyprus. Renewable Energy and Power Quality Journal, pp. 599-604, 2016. DOI: 10.24084/repqj14.406.

[27] Sinos, S., Review of the Vernacular Architecture of Cyprus, Athens, 1976

[28] Nakano, J. \& Tanabe, S., Thermal comfort and adaptation in semi outdoor environments. ASHRAE Transactions, pp. 543-553, 2004. 